\title{
Changes in the depth of chest compressions during cardiopulmonary resuscitation in a pediatric simulator
}

\author{
Diego Enriquez, M.D., ${ }^{a}$ Lorena Firenze, M.D. ${ }^{b}$ Josefina FernándezDíaz, M.D., ${ }^{b}$ \\ Agustín Iglesias, M.D., ${ }^{b}$ Nicolás Falk, M.D., ${ }^{b}$ Pablo Pollini, B.S., ${ }^{a}$ and \\ Edgardo Szyld, M.D. c,d $^{\text {d }}$
}

\begin{abstract}
Introduction. High-quality chest compressions (CCs) are the main component of cardiopulmonary resuscitation (CPR).

Objectives. Toassess the depthofCCsduring CPR using a pediatric patient manikin. A secondary objective was to explore the association between CC depth and sex, level of training, body mass index, and periodic physical training.

Material and methods. Prospective study with experimental observation. Pediatric residents, pediatricians, nurses, and other health care providers trained in CPR and who attended children were included. A software program was used to record the depth of CCs while performing $\mathrm{CPR}$ during 2 minutes. Tiredness was defined as a deterioration in the number of adequately deep CCs $(>50 \mathrm{~mm}$ ) by more than 3 CCs between the first and the last cycles.

Results. A total of 137 subjects participated (85.4\% were women). Only 48 participants $(35.8 \%)$ showed an adequate performance in terms of depth. Significant differences were observed for men $(p<0.0001)$ and trained pediatricians compared to the rest $(p=0.038)$. A worsening was observed in performance in terms of depth after 2 minutes in $36.5 \%$ of participants. No significant differences were observed in relation to body mass index and physical activity.

Conclusions. Depth rate reduced after 2 minutes. No association was observed with the body mass index or regular physical activity of resuscitators but with their sex and level of training.

Key words: chest compression, cardiac massage, fatigue, cardiopulmonary resuscitation, pediatrics.

http: / / dx.doi.org/10.5546/ aap.2018.eng.e730

To cite: Enriquez D, Firenze L, Fernández Díaz J, Iglesias A, et al. Changes in the depth of chest compressions during cardiopulmonary resuscitation in a pediatric simulator. Arch Argent Pediatr 2018;116(6):e730-e735.
\end{abstract}

\section{INTRODUCTION}

Cardiorespiratory arrest (CRA) is an infrequent event in pediatric patients; it occurs in 8 to 20 out of 100000 children per year in the United States of America (USA) and in $1.9-6 \%$ of patients admitted to the pediatric intensive care unit. ${ }^{1-4}$

The results of in-hospital resuscitations have improved over the years and, at present, survival is about $36 \%$ at the time of hospital discharge..$^{2,5-7}$ However, results vary among the different sites, the time of the event, and the place where it occurred; in some cases, a survival rate of approximately $12 \%$ is achieved. . $^{2,3}$ This suggests the need for a fast access to duly trained staff and, given the low frequency of these events, using simulators is of great importance.

High-quality chest compressions (CCs) are still the main component of circulatory support after a CRA. 1,9,10

Tiredness in the resuscitator frequently leads to a reduction in the depth of CCs, thus affecting their effectiveness. In addition, the subjective perception of tiredness is similar when comparing resuscitation in adult and pediatric patients. ${ }^{1,11,12}$ For this reason, international guidelines recommend rotating the person performing cardiopulmonary resuscitation (CPR) every 2 minutes. ${ }^{13}$

No studies have been published in our setting that assessed the sustained depth of CCs in pediatrics; therefore, we decided to conduct this study.

\section{OBJECTIVES}

Primary: To assess the depth of CCs using a pediatric patient manikin during CPR performed by members of the staff of a children's hospital. 
Secondary: To compare the depth of CCs between resuscitators in terms of sex, level of training, body mass index (BMI), and regular physical activity.

\section{MATERIAL AND METHODS}

This was a prospective study with experimental observation, approved by the Ethics Committee of Hospital de Niños "Ricardo Gutiérrez" (HNRG), located in the Autonomous City of Buenos Aires.

CPR was practiced using a feedback simulator at the HNRG facilities and at the Simulación Médica Roemmers (SIMMER) Center. The attendees of 11 pediatric emergency and CPR training workshops organized together by the HNRG and the SIMMER Center were invited to participate in this study. All participants signed the informed consent before study inclusion. Another group of health care providers participated in the study during pre-conference workshops of an academic event carried out at the HNRG. The entire study was performed during 2016 and in the first half of 2017.

Inclusion criteria: All participants in this study were required to have completed and approved a CPR course that included training on how to perform CCs. CPR course completion was confirmed through direct questioning during the informed consent process for this study. Regardless of this, all participants were trained and / or retrained using basic simulators. At least 2 hours elapsed before starting to work on the feedback simulator.

Exclusion criteria: Severe health problems that limited physical activity, a baseline heart rate (HR) above 110 beats per minute, a baseline respiratory rate above 20 breaths per minute or an oxygen saturation level $\leq 92 \%$ at the beginning of observation.

Participants were invited to sign an informed consent for the use of course images and content for research, warranting the elimination of identifiable data and, specifically, for participation in this study.

Study subjects comprised a convenient sample of attendees of any of the workshops at the SIMMER Center or at HNRG.

Observers in this study were different from those who provided basic training on CPR (staff from the SIMMER Center).

Participants were asked to perform 2 minutes of CCs coordinated with bag-mask ventilation (15:2) and were offered the chance to interrupt
CPR if they felt very tired. During this period, participants were expected to complete a total of 10 cycles (approximately, 150 CCs and 20 ventilations). CPR was performed on the ground, on the surface of a thin mat.

Using non-invasive monitoring, oxygen saturation, HR, and respiratory rate were measured in participants before and immediately after the performance of CCs and ventilation for 2 minutes.

Equipment used: The Laerdal Resusci Anne ${ }^{\circledR}$ QCPR ${ }^{\circledR}$ (http: / / www.laerdal.com/la/ ResusciAnne) and the Resusci Anne Wireless Skill Reporter Software (http: / / www.laerdal.com/la / doc/2173/

Quantitative performance measures were obtained using a Heart Start MRx monitor that used the sensor force and the accelerometer technology to measure the rate, depth, force of deflection, and residual force. The device also provided real-time feedback audiovisual images to the resuscitator and/or the trainer, calibrated to the adequate depth and frequency for the patients(it simulated a 14 -year-old, $45-\mathrm{kg}$ patient).

The device's recording system recorded the quality observed and the time elapsed until the resuscitator needed to interrupt CPR due to a selfperceived feeling of tiredness.

An independent observer recorded the results of each performance as shown in the system.

The number of CCs that did not reach the adequate depth $(50 \mathrm{~mm})$ was counted, and the first and the last completed cycles were compared. For this study, tiredness was defined as a deterioration observed in the number of adequately deep CCs by more than 3 CCs between the first and the last cycles.

The following participant outcome measures were recorded: sex $(\%)$, age (mean $+/$ - standard deviation [SD]), profession and level of training, average number of hours spent doing regular physical activity per week (divided into aerobic and anaerobic exercise), presence of an underlying disease that affected physical ability, such as bronchial asthma, congenital heart disease, arterial hypertension, arrhythmia, anemia, etc. Participants' weight, height, and BMI (mean + / - SD, range) were also recorded. For this study, regular physical training was defined according to the World Health Organization's recommendations. ${ }^{14}$

Collected data were entered into an ad-hoc Excel $^{\circledR}$ spreadsheet that identified participants only with their assigned order number. 
Outcome measures were described and descriptive and comparative statistics were used (Student's test or $\chi^{2}$ test, as applicable). A value of $\mathrm{p}<0.05$ was considered statistically significant.

\section{RESULTS}

In the study period, 11 workshops were carried out with a total of 137 participants; none of them met an exclusion criterion. The workshops conducted at the SIMMER Center included CPR training and emergency management; those conducted at the HNRG only consisted in the study as a pre-conference activity. Women accounted for $85.4 \%$ of participants. The average age of participants was 30.9 years $( \pm 7.8)$. Table 1 describes participants' distribution in relation to profession/activity, level of training, BMI, and regular physical activity.

Only 48 participants $(35.8 \%)$ showed an adequate performance in terms of CC depth (>50 mm).

It is worth noting that, for the purpose of our study, performance as mentioned here refers to the depth of CCs. Table 2 describes performance in relation to the average depth of CCs in millimeters ( $\geq 50 \mathrm{~mm}$ or $<50 \mathrm{~mm}$ ) according to participants' level of training and sex. Significant differences were observed for men $(p<0.0001)$ and trained pediatricians compared to the rest $(\mathrm{p}=0.038)$.

A worsening was observed in the performance of $36.5 \%$ of participants when comparing the depth of CCs between the first and the last cycles. Table 3 shows the results of this comparison for all participants and separately for the 68 subjects who started with an adequate performance.

No sex differences were observed in relation to the worsening of CC depth between the first and the last cycle in more than 3 CCs.

Table 4 shows the presence of tiredness (as defined in this study) and its classification by sex,
BMI, and regular physical activity.

The mean depth and SD of CCs was $45.8 \mathrm{~mm}$ ( \pm 5.9$)$ among women and $52.8( \pm 3.7)$ among men $(\mathrm{p}<0.0001)$.

Participants' HR in the beginning of CPR was 85 beats per minute in average, with a SD of \pm 13.07. It increased significantly after 2 minutes of doing CCs, to 127 beats per minute (SD \pm 23.2$)$ $(\mathrm{p}<0.001)$.

\section{DISCUSSION}

This prospective, experimental study in health care staff who completed and approved a CPR course and who provide care to the pediatric population found that only half of participants showed an adequate performance in terms of the minimum depth required for CCs. In addition, a marked reduction was observed in the quality of CCs after 2 minutes of simulated CPR.

TABLE 1. Characteristics of the population

\begin{tabular}{lcc}
\hline Profession/Activity $(\mathbf{n}=\mathbf{1 3 7})$ & $\mathbf{N}$ & $\%$ \\
\hline Pediatrician & 14 & 10.2 \\
Pediatric resident & 93 & 67.9 \\
Nurse & 24 & 17.5 \\
Other* & 6 & 4.4 \\
BMI $(\mathrm{n}=137)$ & & \\
$<18.5$ & 7 & 5.10 \\
$<18.5-24.9$ & 98 & 71.50 \\
$>25-29.9$ & 24 & 17.50 \\
$>30$ & 8 & 5.80 \\
Physical activity $(\mathrm{n}=137)$ & & \\
Aerobic exercise & & \\
$<2$ hours per week & 64 & 46.70 \\
2 to 5 hours per week & 66 & 48.20 \\
$>5$ hours per week & 7 & 5.10 \\
Anaerobic exercise $(\mathrm{n}=137)$ & & \\
$<2$ hours per week & 119 & 86.90 \\
$>2$ hours per week & 18 & 13.10 \\
\hline
\end{tabular}

BMI: body mass index.

${ }^{*}$ Other profession/activity: B.S. in Kinesiology, Biochemistry.

TABLE 2. Performance of chest compressions by level of training and sex

\begin{tabular}{|c|c|c|c|}
\hline $\begin{array}{l}\text { Outcome measure/performance relative } \\
\text { to the averagedepth of chest compressions }\end{array}$ & $\begin{array}{c}\text { Adequate } \\
(>50 \mathrm{~mm}) \\
\mathrm{N}(\%)\end{array}$ & $\begin{array}{c}\text { Poor } \\
\text { (<50 mm) } \\
\text { N ( \%) }\end{array}$ & $p$ value \\
\hline Sex & & & \\
\hline $\begin{array}{l}\text { Male, } \mathrm{n}=20 \\
\text { Female, } \mathrm{n}=117\end{array}$ & $\begin{array}{c}16(80) \\
33(28.2)\end{array}$ & $\begin{array}{c}4(20) \\
84(71.8)\end{array}$ & $<0.0001$ \\
\hline $\begin{array}{l}\text { Level of training } \\
\text { Pediatricians, } \mathrm{n}=14 \\
\text { Pediatric residents, } \mathrm{n}=93 \\
\text { Nurses, } \mathrm{n}=24 \\
\text { Other, } \mathrm{n}=6\end{array}$ & $\begin{array}{c}9(64.3) \\
33(35.5) \\
8(33.3) \\
3(50)\end{array}$ & $\begin{array}{c}5(35.7) \\
60(64.5) \\
16(66.7) \\
3(50)\end{array}$ & $\begin{array}{c}0.0379 \\
0.263 \\
0.553 \\
0.56\end{array}$ \\
\hline
\end{tabular}


The progressive deterioration in the quality of CCs has been previously described in studies using adult, pediatric, and neonatal patients manikins. ${ }^{1,11,12,15}$ The current recommendation to rotate the resuscitator every 2 minutes is mostly based on studies conducted in simulators. ${ }^{13}$

CCs imply significant physical effort, equivalent to running, and it is estimated that they require a power of up to $144.1 \mathrm{~W}$ in children and of up to $166.5 \mathrm{~W}$ in adults.1,10 This explains the significant increase in participants' HR observed in our study and the progressive deterioration in the quality of CCs over the test duration.

Sutton et al. recently published a study that analyzed the data of 15 pediatric CPRs and found that only $20 \%$ of CCs had reached the recommended depth $(\geq 50 \mathrm{~mm}){ }^{16}$

The same authors analyzed CPR in 87 pediatric patients and described that those who received CCs that complied with the expected depth $(\geq$ $50 \mathrm{~mm}$ ) survived beyond $24 \mathrm{~h} \cdot{ }^{17}$ Another study in adults showed a higher survival rate among patients who had received CPR out of the hospital with CCs whose depth was $\geq 50 \mathrm{~mm} .{ }^{18}$

These findings reinforce the importance of improving training and assessing performance periodically. This implies a great challenge because CPR in pediatric patients is infrequent.

TABLE 3. Difference between the first and the last cycles (adequate depth or depth below the minimum required as evidence of tiredness)

\begin{tabular}{|c|c|c|c|c|}
\hline \multirow{2}{*}{$\begin{array}{l}\text { WORSENING } \\
\text { (Difference of }>3 \text { CCs with a depth below the required level) }\end{array}$} & \multicolumn{2}{|c|}{ All participants } & \multicolumn{2}{|c|}{$\begin{array}{l}\text { Participants who } \\
\text { start with good } \\
\text { performance }\end{array}$} \\
\hline & 50 & $36.50 \%$ & 22 & $32.40 \%$ \\
\hline $\begin{array}{l}\text { MAINTENANCE } \\
\text { (Difference of }<3 \text { CCs with a depth below the required level) }\end{array}$ & 64 & $46.70 \%$ & 27 & $39.70 \%$ \\
\hline $\begin{array}{l}\text { IMPROVEMENT } \\
\text { (A lower number of CCs with a depth below the required levelin the last cycle) }\end{array}$ & 23 & $16.80 \%$ & 19 & $27.90 \%$ \\
\hline TOTAL & 137 & & 68 & \\
\hline
\end{tabular}

CCs: Chest compressions.

TABLE 4. Presence and absence of tiredness (based on the criterion adopted for this study for deterioration in the depth of chest compressions between the first and the last cycles) by sex, body mass index, and regular physical activity

\begin{tabular}{|c|c|c|c|}
\hline & Tiredness n (\%) & No tiredness n ( \%) & p value \\
\hline \multicolumn{4}{|l|}{ Sex } \\
\hline Male, $n=20$ & 6 & 14 & \\
\hline Female, $\mathrm{n}=117$ & 44 & 73 & 0.51 \\
\hline \multicolumn{4}{|l|}{ Profession/Activity } \\
\hline Pediatricians, $\mathrm{n}=14$ & 4 & 10 & 0.516 \\
\hline Pediatric residents, $\mathrm{n}=93$ & 36 & 57 & 0.434 \\
\hline Nurses, $\mathrm{n}=24$ & 8 & 16 & 0.723 \\
\hline Other, $\mathrm{n}=6$ & 2 & 4 & 0.869 \\
\hline \multicolumn{4}{|l|}{ BMI } \\
\hline$<18.5, \mathrm{n}=7$ & $3(42.9)$ & $4(57.1)$ & 0.720 \\
\hline$<18.5-24.9, \mathrm{n}=98$ & $39(39.9)$ & $59(60.2)$ & 0.203 \\
\hline$>25-29.9, \mathrm{n}=24$ & $5(20.8)$ & $19(79.2)$ & 0.079 \\
\hline$>30, \mathrm{n}=8$ & $3(37.5)$ & $5(62.5)$ & 0.952 \\
\hline \multicolumn{4}{|l|}{ Physical activity } \\
\hline \multicolumn{4}{|l|}{ Aerobic exercise } \\
\hline$<2$ hours per week & 25 & 39 & 0.559 \\
\hline 2 to 5 hours per week & 22 & 44 & 0.458 \\
\hline$>5$ hours per week & 3 & 4 & 0.720 \\
\hline \multicolumn{4}{|l|}{ Anaerobic exercise } \\
\hline$<2$ hours per week & 43 & 76 & 0.821 \\
\hline$>2$ hours per week & 7 & 11 & \\
\hline
\end{tabular}

BMI: body mass index. 
Different ideas have been suggested to overcome these difficulties, such as refresher courses.Very recently, Niles et al. published the positive effect of reviewing CPR training at least every 6 months. ${ }^{19}$

In our study, it was observed that a greater proportion of women failed to achieve a depth $\geq 50 \mathrm{~mm}$. Ochoa et al. did not find differences in this regard in a study with adult patient manikins; however, in a study published by Ashton et al., also conducted in adult patient manikins, men showed a better performance doing CCs. ${ }^{11,12}$

Our study found significant differences in the level of tiredness compared to the level of training (in favor of trained pediatricians). Other studies have established that differences in performance are observed when comparing different health care facilities. ${ }^{20}$

It was striking that a small group of participants improved their performance towards the end of the test. It may be speculated that they improved the technique as a result of selfperception of the initial error in depth and its subsequent correction.

The fact that this study included participants from a single site is one of its limitations. In addition, in spite of including a large number of participants, the study population was restricted to those who attended training and pre-conference workshops, so the sample's representativeness was limited.

This was a convenience sample so, in some observed outcomes, the " $\mathrm{n}$ " value was too small to establish statistical differences. This was observed, above all, in the little number of male participants.

In addition, this was a study done using simulators but, as mentioned above, it was really difficult to obtain information about the clinical performance during such an infrequent event.

If these findings were observed in other settings, it would be important to assess and reinforce training on how to perform CCs in the pediatric field periodically so that health care staff is prepared to act in the case of a cardiac arrest in a pediatric patient.

\section{CONCLUSIONS}

Most participants performed CCs at a lower depth than expected. Depth rate reduced after 2 minutes. No association was observed between the CCs performance and the BMI and regular physical activity of resuscitators, but with their sex and level of training.

\section{REFERENCES}

1. Badaki-Makun O, Nadel F, Donoghue A, et al. Chest compression quality over time in pediatric resuscitations. Pediatrics. 2013; 131(3):e797-804.

2. Bhanji F, Topjian AA, Nadkarni VM, et al. Survival Rates Following Pediatric In-Hospital Cardiac Arrests During Nights and Weekends. JAMA Pediatr. 2017; 171(1):39-45.

3. Alten JA, Klugman D, Raymond TT, et al. Epidemiology and Outcomes of Cardiac Arrest in Pediatric Cardiac ICUs. Pediatr Crit Care Med. 2017; 18(10):935-43.

4. Padiyath A, Rettiganti M, Gossett JM, et al. Epidemiology and outcomes of cardiac arrest among children with Down Syndrome: a multicenter analysis. Minerva Anestesiol.2017; 83(6):574-81.

5. DonoghueAJ,AbellaBS,MerchantR, etal.Cardiopulmonary resuscitation for in-hospital events in the emergency department: Acomparison of adult and pediatric outcomes and care processes. Resuscitation. 2015; 92:94-100.

6. Slonim AD, Patel KM, Ruttimann UE, Pollack MM. Cardiopulmonary resuscitation in pediatric intensive care units. Crit Care Med. 1997; 25(12):1951-5.

7. Meyer L, Stubbs B, Fahrenbruch C, et al. Incidence, causes, and survival trends from cardiovascular-related sudden cardiac arrest in children and young adults 0 to 35 years of age: a 30-year review. Circulation. 2012; 126(11):1363-72.

8. Epstein AE, Powell J, Yao Q, et al. In-hospital versus outof-hospital presentation of life-threatening ventricular arrhythmias predicts survival: results from the AVID Registry.AntiarrhythmicsVersus ImplantableDefibrillators. I Am Coll Cardiol. 1999; 34(4):1111-6.

9. Abella BS, Sandbo N, Vassilatos P, et al. Chest compression rates during cardiopulmonary resuscitation are suboptimal: a prospective study during in-hospital cardiac arrest. Circulation. 2005; 111(4):428-34.

10. Jetté M, Sidney K, Blumchen G. Metabolic equivalents (METS) in exercise testing, exercise prescription, and evaluation of functional capacity. Clin Cardiol. 1990; 13(8):555-65.

11. Ochoa FJ, Ramalle-Gómara E, Lisa V, Saralegui I. The effect of rescuer fatigue on the quality of chest compressions. Resuscitation. 1998; 37(3):149-52.

12. Ashton A, McCluskey A, Gwinnutt CL, Keenan AM. Effect of rescuer fatigue on performance of continuous external chest compressions over 3 min. Resuscitation. 2002; 55(2):151-5.

13. Monsieurs KG, Nolan JP, Bossaert LL, et al. European Resuscitation Council Guidelines for Resuscitation 2015: Section 1. Executive summary. Resuscitation. 2015; 95:1-80.

14. Organization Mundial de la Salud. Recomendaciones mundiales sobre actividad física para la salud. 2010. [Accessedon:July17th,2018].Availableat:http: / / apps.who. int / iris / bitstream/ handle/10665/44441/9789243599977_ spa. pdf;jsessionid=45E7B52A63A1D02C5D2C08612B73 $1 \mathrm{D} 03$ ? sequence $=1$.

15. Li ES, Cheung PY, O'Reilly M, et al. Rescuer fatigue during simulated neonatal cardiopulmonary resuscitation. J Perinatol. 2015; 35(2):142-5.

16. Sutton RM, Niles D, French B, et al. First quantitative analysis of cardiopulmonary resuscitation quality during in-hospital cardiac arrests of young children. Resuscitation. 2014; 85(1):70-4.

17. Sutton RM, French B, Niles DE, et al. 2010 American Heart Association recommended compression depths during 
pediatric in-hospital resuscitations are associated with survival. Resuscitation. 2014; 85(9):1179-84.

18. Vadeboncoeur T, Stolz U, Panchal A, et al. Chest compression depth and survival in out-of-hospital cardiac arrest. Resuscitation. 2014; 85(2):182-8.
19. Niles DE, Nishisaki A, Sutton RM, et al. Improved Retention ofChestCompression PsychomotorSkills With Brief "Rolling Refresher" Training. Simulhealthc. 2017; 12(4):213-9.

20. Auerbach M, Whitfill T, Gawel M, et al. Differences in the Quality of Pediatric Resuscitative Care Across a Spectrum of Emergency Departments. JAMAPediatr. 2016;170(10):987-94. 